\title{
Reducing the discrepancy between regional specific electricity consumption as a way to increase the structural stability of the Russian economy
}

\author{
Sergey Nekrasov* \\ CEMI RAS, Nakhimovsky prospect, 47, 117418 Moscow, Russia
}

\begin{abstract}
In 2010-2020 the dynamics and absolute values of regional per capita electric power consumption (EPC) in the European part of Russia was comparable with similar indicators in Western European countries, and in the Asian part - with the countries of Northern Europe, the USA and Canada. If all over the world there is a reduction in the differentiation in energy consumption between developing and developed countries, then in Russia in 1990-2012 this indicator increased, which reflects the ongoing decline in the structural stability of the domestic economy. The change in this negative trend in 2012-20018 shown on the tools of the theory of technocenoses. The need to concentrate efforts not on the growth of the EPC in regions with developed production and primary redistribution of natural resources, but on reducing the divergence of regions in terms of the value of the EPC is substantiated. In regions with low EPC, the problem is not a shortage of electricity, but the weak development of industrial and agricultural production.
\end{abstract}

\section{Introduction}

The study of energy problems, its development and evolution has shown that the key information that determines the dominant part of modern development is concentrated in the dynamics of the gross product and energy consumption. Regardless of the method of calculating GDP, a simple linear correlation between the product produced and the consumed energy is clearly traced [1]. Today "energy is not a branch of the economy, but a system for transforming all potential resources into the aggregate capital of society" [2].

The growth in electricity consumption will outstrip the growth in consumption of other energy carriers and, according to the IEA baseline forecast, will amount to $60 \%$ of the current level by 2040 [3]. Electricity consumption is increasing both as a result of population growth and an increase in specific per capita electricity consumption (EPC, MWh / person per year). Against the background of equalization of specific energy consumption between developed and developing countries [4], in the latter, the growth rates of EPC remain high.

\footnotetext{
* Corresponding author: san693@mail.ru
} 
Both in speed and in the necessary scale of meeting demand due to the equalization of energy consumption between the developing and the developed world, society has already approached the limit of resource possibilities. The population size is related to the standard of living of people, and under sufficiently comfortable conditions, stabilization in this indicator is observed throughout the world [5]. If in 1960-1970 the difference in specific energy consumption in developed and developing countries was more than 20 times, then by the 2010-2020 it decreased by about 7 times [6]. Despite the fact that, for example, more than $50 \%$ of USA companies with sales of more than $\$ 1$ billion either continue to transfer jobs back to the country, or plan to do so in the near future [7], EPS in developed countries does not increase. Increasingly, a distinctive feature of such countries is the cessation of the growth of the EPS and its arrival at the asymptotic level. This pattern was identified in the early 1970s. Since that time, per capita consumption in California has not increased and does not exceed 7.5 MWh / person. per year [8]. But if in the 2000-2010 this pattern had a pronounced character in the countries of Northern Europe, Great Britain, Canada, the USA, Australia (highlighted in italics in the Table) and only began to manifest itself in Western European countries and Japan [9], then in the 2010-2020 the lack of growth in EPS has become characteristic of most developed countries. As a result, there is evidence of the stabilization of the EPS at a value of less than $8 \mathrm{MW} \cdot \mathrm{h} /$ person. per year for the countries of Western Europe and Japan and at the level of $\sim 12 \mathrm{MW} \cdot \mathrm{h} /$ person. per year for the Nordic countries, the USA and Canada.

Table 1. EPS dynamics in developed countries

\begin{tabular}{|l|c|c|c|c|c|c|c|c|c|}
\hline \multirow{2}{*}{ Country } & \multicolumn{3}{|c|}{ EPC, MW · h / person. per year } & \multicolumn{3}{c|}{$\begin{array}{c}\text { Average annual change in } \\
\text { EPC,\% / year }\end{array}$} \\
\cline { 2 - 11 } & 1990 & 2000 & 2006 & 2012 & 2018 & $\begin{array}{c}1990- \\
2000\end{array}$ & $\begin{array}{c}2000- \\
2006\end{array}$ & $\begin{array}{c}2006- \\
2012\end{array}$ & $\begin{array}{c}2012- \\
2018\end{array}$ \\
\hline Norway & 23,1 & 24,9 & 23,8 & 23,2 & 23,7 & $0,7 \%$ & $-0,7 \%$ & $-0,4 \%$ & $0,4 \%$ \\
\hline Canada & 15,6 & 16,5 & 16,4 & 15,6 & 14,3 & $0,6 \%$ & $-0,1 \%$ & $-0,8 \%$ & $-1,5 \%$ \\
\hline Sweden & 15,3 & 15,2 & 14,9 & 13,9 & 13,2 & $0,0 \%$ & $-0,4 \%$ & $-1,2 \%$ & $-0,9 \%$ \\
\hline USA & 10,9 & 12,9 & 12,8 & 12,2 & 12,2 & $1,7 \%$ & $-0,1 \%$ & $-0,8 \%$ & $-0,1 \%$ \\
\hline Australia & 7,85 & 9,63 & 9,81 & 9,77 & 9,29 & $2,1 \%$ & $0,3 \%$ & $-0,1 \%$ & $-0,8 \%$ \\
\hline Japan & 6,20 & 7,56 & 7,85 & 7,58 & 8,06 & $2,0 \%$ & $0,6 \%$ & $-0,6 \%$ & $1,0 \%$ \\
\hline Netherlands & 4,95 & 6,26 & 6,73 & 6,45 & 6,73 & $2,4 \%$ & $1,2 \%$ & $-0,7 \%$ & $0,7 \%$ \\
\hline France & 5,55 & 6,78 & 7,01 & 6,88 & 6,58 & $2,0 \%$ & $0,6 \%$ & $-0,3 \%$ & $-0,7 \%$ \\
\hline Germany & 6,06 & 6,10 & 6,60 & 6,71 & 6,38 & $0,1 \%$ & $1,3 \%$ & $0,3 \%$ & $-0,8 \%$ \\
\hline Italy & 3,86 & 4,90 & 5,47 & 5,16 & 5,01 & $2,4 \%$ & $1,8 \%$ & $-1,0 \%$ & $-0,5 \%$ \\
\hline Great Britain & 4,96 & 5,79 & 5,82 & 5,10 & 4,62 & $1,6 \%$ & $0,1 \%$ & $-2,2 \%$ & $-1,6 \%$ \\
\hline
\end{tabular}

\section{Materials and Methods}

In the Russian Federation, there are two types of territories by the volume of electricity consumption per capita: the western part (NWFD, Central Federal District, Volga Federal District, Southern Federal District and North Caucasus Federal District), and the eastern part (UFO, Siberian Federal District, Far Eastern Federal District). In 2010 an assumption was made about the absence of reasons for the growth of SEC in the western part above the level of Western Europe and Japan ( $8 \mathrm{MWh}$ / person per year), and in the east of the country above the level of the USA, Canada and Northern European countries (12 MWh / person per year) [9], the validity of which is confirmed by the regional dynamics of power consumption in the 
last decade. Electricity consumption in comparison with 1990 remained unchanged with an accuracy of 3\%. In 2016, this indicator reached the level of 1990 (1073.839 billion $\mathrm{kWh}$ ) in 2016 and by 2018 increased by 3\% (to 1108.134 billion kWh). However, consumption in the regions was multidirectional. In regions - large consumers with a consumption volume of more than 20 billion $\mathrm{kWh}$ / year, an increase in electricity consumption was observed: in the Tyumen region by $51 \%$, in Moscow by $50 \%$, in St. Petersburg by $44 \%$, in the Krasnodar region by $37 \%$, in the Moscow region by $29 \%$, in the Leningrad region by $27 \%$. Electricity consumption increased by more than $25 \%$ in the Kaliningrad, Tomsk, Sakhalin Regions and the Trans-Baikal Territory, the Republics of Adygea, Altai, Dagestan and Ingushetia.

A feature of regions with a clearly expressed negative dynamics is their small volume of electricity consumption - less than 4 billion $\mathrm{kWh} \mathrm{/} \mathrm{year.} \mathrm{There} \mathrm{is} \mathrm{an} \mathrm{increase} \mathrm{in} \mathrm{the}$ discrepancy between Russian regions on this indicator. In 1990-2018 the fall in electricity consumption in the Ivanovo region was $48 \%$, the Republics of Kalmykia, North Ossetia, Mari El and Tambov, Kurgan, Magadan, Oryol, Bryansk regions decreased by a third or more.

Over this period, the EPS increased by 3.7\% (7.27 and 7.54 MWh / person per year). But in the regions, the dynamics of the EPS, as well as the dynamics of the volumes of electricity consumption, is multidirectional. In 1990-2018 the leaders in terms of EPS growth were the Kaluga and Sakhalin regions with an increase of more than $90 \%$, the Republic of Khakassia and the Magadan regions with an increase of more than $70 \%$. During this period, a decrease in the EPS by more than $47 \%$ occurred in the Republics of Chechnya and North Ossetia, by more than $37 \%$ in Kalmykia and Kabardino-Balkaria, by $30 \%$ or more in the Volgograd and Ivanovo regions, the Republic of Mari El. In 2014-2018 the growth leaders were Sevastopol, where the EPS growth was $36 \%$ with an increase in this indicator in Crimea by $4 \%$. Apparently, this is due not so much to the mass installation of air conditioners as to the establishment of metering of electricity consumption in the city and, accordingly, to a decrease in commercial losses in the power grids (unaccounted consumption is reduced). As a result, the EPS of Sevastopol became $4.8 \mathrm{MW} \cdot \mathrm{h}$ / person per year, which is a characteristic value for the cities of Russia - Moscow, where EPS increased in 1990-2018 from 4.2 to 4.5 $\mathrm{MWh} /$ person per year, and St. Petersburg, where the EPS for 28 years has grown from 3.9 to $5.3 \mathrm{MW} \cdot \mathrm{h} /$ person. in year. The general pattern - a lower level of EPS in the capital and large cities in comparison with the average value in the state is inherent in all developed countries [10].

As a result of studying the features of regional power consumption using the tools for managing the sustainability of economic systems based on the theory of technocenoses [11, $12,13]$, developed in the course of research $[14,15]$, it was found that if all regions are arranged according to the volume of electricity consumption, then it will be obtained $\mathrm{H}$ distribution $\mathrm{A}(\mathrm{x})=\mathrm{A}_{1} / \mathrm{x}^{\beta}$, where $\mathrm{x}$ is the number of the region in order, $\beta$ is the characteristic parameter of the technocenosis. Russian regions are technocenosis. As elements of any technocenosis in terms of power consumption, they are linked by weak ties [16]. The distribution of Russian regions in 2018 with more than $80 \%$ reliability is described by the Hdistribution (Fig. 1): in total, the share of the first 6 regions of the leaders (Tyumen, Irkutsk, Sverdlovsk, Moscow regions, Moscow and Krasnoyarsk Region) accounted for $32.5 \%$ of all electricity consumption in the country; the share of 6 regions with the minimum consumption is $0.43 \%$. These are the Republics of Kalmykia, Altai, Tyva, Karachay-Cherkessia, the Chukotka Region, and the Jewish Autonomous Region. Annual electricity consumption in the Tyumen Region and the Republic of Kalmykia differed by 182 times. 


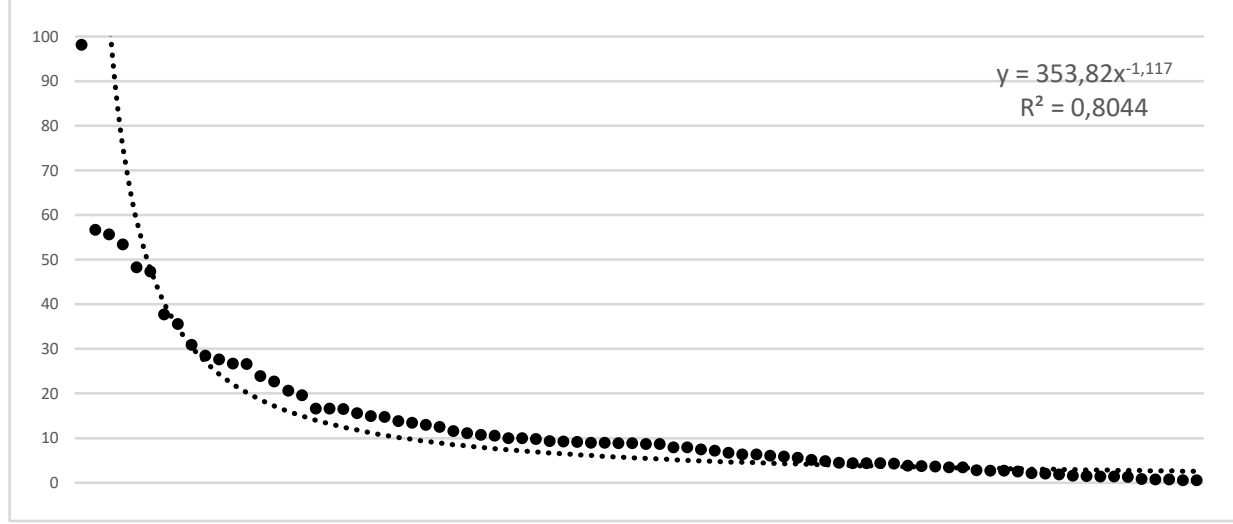

Fig. 1. Distribution of regions of the Russian Federation by volume of electricity consumption in 2018 (billion $\mathrm{kWh} /$ year)

If the distribution of regions by volume of electricity consumption from the point of view of the theory of technocenoses has been studied for more than 20 years [16], then the patterns of regional distribution according to EPC are insufficiently studied. The distribution of regions by EPS is also described by the H-distribution (Fig. 2). The highest EPS in 2018 - in the Republic of Khakassia and the Tyumen Region 30.9 and 26.6 MWh / person. per year, the least - in the Republics of Ingushetia and Kabardino-Balkaria 1.6 and 1.9 MWh / person in year. The ratio of the maximum and minimum EPS in Russia is slightly less than 20 times. Such a high differentiation, several times exceeding the 5-fold difference in the EPS of developed countries (Table), is a consequence of the imbalances in the development of the Russian economy accumulated in the previous decades.

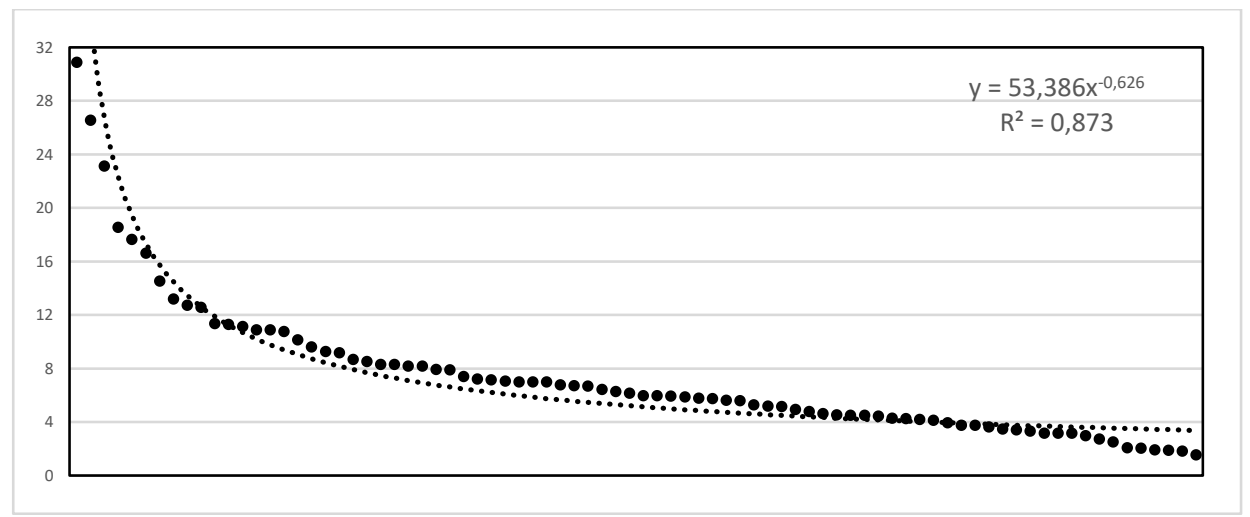

Fig. 2. Distribution of Russian regions by EPS in 2018

\section{Results and discussion}

A joint analysis of the dynamics of the population size and the volume of electricity consumption leads to the following conclusions.

The negative dynamics of population growth is a more inertial phenomenon in comparison with changes in electricity consumption: an improvement in the economic indicators of the region, the development of industrial production over a decade, which is happening even as intensively as in the Kaluga region, is not a sufficient condition for stopping depopulation. 
There is a redistribution of the population from the northern territories with high EPS (Murmansk, Vologda, Arkhangelsk regions, Perm Territory, the Republics of Komi and Karelia, Perm Territory; Irkutsk, Magadan, Kemerovo, Amur regions, Chukotka, etc.) to regions with much lower EPS. Therefore, despite the growth of the EPS in most regions separately, in the country as a whole, this indicator is practically constant (for 1990-2018 it grew by $3.7 \%$, and for $2014-2018$ - by $1.8 \%$ ).

There are objective prerequisites for differences in the volume of electricity consumption of the Chukotka and the Tyumen Region, the Republics of Kalmykia and Tatarstan, the Moscow and Oryol Regions (area of the territory, population, etc.). But the reasons for the 20 -fold difference in the per capita electricity consumption of citizens of one state living in different regions, such prerequisites are much less. Closing the gap in per capita energy consumption is a general pattern in the development of the world economy, reflecting the fact that, as a result of the improvement in the well-being of people in developing countries, the historical causes of their energy poverty are gradually becoming secondary. It can be argued that the inhabitants of regions with the EPS, which differ by 10 , and even more 20 times, hardly have equal opportunities for the development of various types of economic activity. From such a significant difference in the EPS it follows that in the economic space, which has been unified for more than a hundred years, two groups of regions are currently united:

- in which the level of electrical equipment of residents is similar to this indicator in developed countries;

- energy deficient regions. In these regions, residents can compare their level of electrical equipment not with developed, but with developing countries.

At the first stage, reducing the divergence of Russian regions in terms of EPS at the first stage to at least 7-fold, a value comparable to a 5-fold difference in EPS of developed countries, is a task of strategic importance for ensuring the structural stability of Russia's socio-economic development. Without its solution, the citizens of these two groups of regions will hardly be able to maintain a sense of belonging to a single economic space.

The level of divergence of technocenosis elements is characterized by the $\beta$ coefficient in the H-distribution formula. An analysis of its dynamics indicates that since 2012, there has been a decrease in the differentiation of regions both in terms of the volume of electricity consumption and in terms of energy consumption. This relationship persists when considering the technocenosis of Russian regions both without including its new elements (the Republic of Crimea and Sevastopol), and taking them into account after 2014 (as shown in Fig. 3 (a) and 3 (b)). Despite the common features, it should be noted a number of differences in the dynamics of $\beta$ in the distribution of regions in terms of the volume of electricity consumption and in terms of energy consumption.

After a rapid increase in the absolute value of both indicators in 1990-1995 the rate of further divergence of Russian regions in terms of electricity consumption decreased, but the overall trend remained unchanged over the next 15 years. Qualitative changes in the direction of the process took place in 2012 .

Intensive divergence of regions by the value of the EPS continued in 1990-2000. In 20002012 the process of decreasing the structural stability of the regional economy stopped, and the movement towards the convergence of the indicators of the electric power supply of Russian citizens began in 2012.

Thus, the toolkit of the theory of technocenoses makes it possible to identify the social processes taking place in the country:

- the accumulation of structural imbalances in the national economy, which in terms of electricity consumption was expressed in the discrepancy in the level of power supply of Russian regions in 1990-2000;

- stabilization of the achieved state in the "fat" 2000-2010, 
- the beginning of qualitative changes, the transition to an increase in the structural stability of the Russian economy as a system after 2012 .

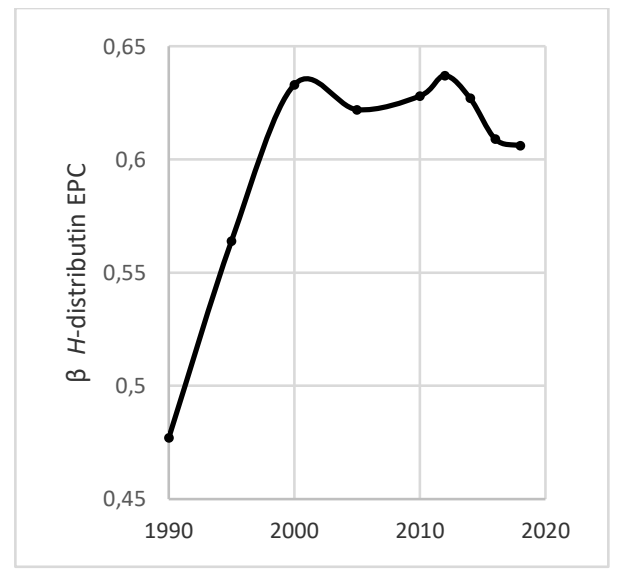

(a)

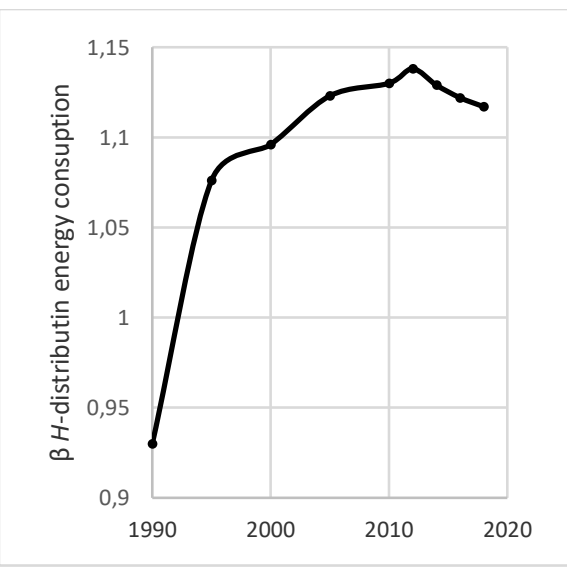

(б)

Fig. 3. Dynamics of the $\beta$ coefficient in the H-distributions of regions by the value of EPS (a) and by the volume of electricity consumption (b)

According to the general organizational science - tectology [17], any change in the structural stability of the system can be expressed quantitatively. Restoring the structural stability of Russian regions in 2012-2018 from the decline in 1990-2012 by EPS was more than $19 \%$, and by the amount of power consumption $10 \%$. As a result, the level of unevenness of Russian regions in terms of the volume of electricity consumption returned to the value of 2004, and according to the EPS by 1997.

Today, in 19 regions of Russia, EPS is less than $4 \mathrm{MWh} /$ person per year. Unlike developing countries, where the limiting factor in electricity consumption is the ability to generate electricity with existing capacities, in these regions the problem is not in increasing production, but in the absence of opportunities to increase electricity consumption at the current level of socio-economic development. The problem is low power consumption due to the underdeveloped industrial and agricultural production in these regions. The "bottleneck" [17] is not the energy shortage of the regions, not the technical possibility of increasing the production of electricity supply. The conclusion about the need to build up energy capacities and build new power plants, which can be obtained when considering the problem at the sectoral level, is fundamentally incorrect. In accordance with the law of least "the stability of the whole depends on the smallest relative resistances of all its parts at any moment" [17]. Therefore, today's efforts should be focused not on the growth of electricity consumption in regions with high EPS, but on supporting the increase in electricity consumption in regions with low EPS. The convergence of the level of electrical equipment as an opportunity to increase labor productivity between different territories of Russia is by eliminating the structural imbalances accumulated over the previous decades.

\section{Conclusions}

The global growth in energy consumption is due to the growth of its per capita consumption in developing countries to the level of developed countries. Since the 1960 the ratio of energy consumption of residents in these two groups of countries has decreased from 20 to 7 times. In Russia in 1990-2018 the ratio of EPS in different regions increased from 7 to 20 times, 
which is a reflection of the accumulation of deformations of socio-economic development, leading to a decrease in the structural stability of the country's economy.

The Russian economy is characterized by an increase in the number of population in regions with a relatively low EPS (Moscow, St. Petersburg, Kuban, North Caucasus Federal District) in its decline in regions with a high EPS.

Based on the tools of the theory of technocenoses, it is shown, that there has been a qualitative change in the dynamics of the structural stability of the domestic economy. Its decline in 1990-2012 changed to recovery. Quantitative indicators of what is happening in 2012-2018 were obtained reducing the discrepancy between Russian regions in terms of electricity consumption and in terms of energy consumption. The decrease in the discrepancy in terms of the volume of electricity consumption was $10 \%$, and for the EPS $20 \%$ of the level of decline for 1990-2012.

By increasing the structural stability is to ensure the reduction of the current 20 -fold gap in the electrical power supply of residents of various regions of Russia. To support the process of convergence of Russian regions in terms of electrical equipment, which began in 2012, it is necessary to focus efforts not on the growth of electricity consumption in regions with a high EPS, which specialize in the extraction of natural resources and industries of the first processing (metallurgy), but to increase electricity consumption in outsider regions.

If the energy poverty of developing countries is due to the lack of energy capacities, then the low level of EPS in Russian regions is caused by the weak development of the electricity consumption

\section{References}

1. E.P. Velikhov, Proceedings of the Moscow Institute of Physics and Technology, 3(4), 6 (2011)

2. V.V. Bushuev, Energy potential and sustainable development. Moscow: IAC "Energy", 320 (2006)

3. World Energy Outlook (WEO-2018) (2020), https://www.iea.org/

4. Adolfo Maza, José Villaverde, Energy Policy, 36(11), 4255 (2008)

5. Velikhov E.P., Energy: economics, technology, ecology, 11, pp. 2 (2009)

6. Velikhov E.P., Proceedings of the Moscow Institute of Physics and Technology, 3(4), 6 (2011)

7. The Boston Consulting Group. Made in America Again, Why Manufacturing Will Return to the USA (2011), https://www.bcg.com/

8. Nekrasov S.A., Grachev I.D., Problems of forecasting, 1, 99 (2020)

9. Nekrasov S.A., Shevchenko I.S., Energetika Tatarstan, 1, 50 (2011)

10. Plan for the sustainable development of energy supply Toronto. Energy Efficiency and Beyond. Toronto's Sustainable Energy Plan, (2007), http://www.toronto.ca/

11. Kuzminov A.N., Regional Economy, 7(2), 28 (2009)

12. Kuzminov A.N., Economic Bulletin of Rostov State University, 5(4), 2, 127 (2007)

13. Fufaev V.V., Economic cenoses of organizations, 86 (2006)

14. Kudrin B.I., Classics of technical cenoses. General and applied cenology, 31 (2006)

15. Gnatyuk V.I., The law of optimal construction of technocenoses, 384 (2005)

16. Electrician, 6, 3 (2001)

17. Bogdanov A.A., Tectology: General Organizational Science, 1, 304 ; 2, 352 (1989) 